\section{Incidence of inflammatory bowel disease in patients with ankylosing spondylitis}

Ankylosing spondylitis is a long-term inflammatory disease that always affects the spine joints. The association between ankylosing spondylitis and other diseases has been extensively assessed. ${ }^{12}$ Recently a cohort study conducted by Schreiber $e$ al published in Annals of the Rheumatic Diseases found that the new-onset cases of inflammatory bowel disease were uncommon in patients with ankylosing spondylitis on secukinumab therapy $(1.13 \%, 9 / 794){ }^{3}$ In order to examine the association between ankylosing spondylitis and inflammatory bowel disease in a different country, a preliminary cohort study was undertaken using the 2005-2012 database of the Taiwan National Health Insurance Programme with 23 million residents living in Taiwan. ${ }^{4}$ Subjects ages $20-84$ with a new diagnosis of ankylosing spondylitis were identified as the ankylosing spondylitis group (International Classification of Diseases, Ninth Revision code (ICD-9 code 720.0)). For every subject with ankylosing spondylitis, four sex-matched and age-matched subjects who did not have a diagnosis of ankylosing spondylitis were assigned as the non-ankylosing spondylitis group. The main outcome was a new diagnosis of inflammatory bowel disease (ICD-9 code 555-556). Table 1 presents that the overall incidence of inflammatory bowel disease was lower in the ankylosing spondylitis group than in the non-ankylosing spondylitis group, but without reaching statistical significance ( 1.41 vs 1.79 per 1000 person-years, incidence rate ratio $0.79,95 \%$ CI 0.48 to $1.28 ; \mathrm{p}=0.332$ ). As stratified by sex and age, there was no statistical significance in the incidence of inflammatory bowel disease between the ankylosing spondylitis group than the non-ankylosing spondylitis group.

Some caveats are discussed. Previous studies found that the prevalence of ankylosing spondylitis in patients with inflammatory bowel disease was around $3.7 \%-4.5 \% .^{56}$ One review found that the prevalence of inflammatory bowel disease in patients with ankylosing spondylitis was around 6\%-14\%. ${ }^{7}$ Due to both conditions likely occurring concomitantly, some researchers suggest that ankylosing spondylitis and inflammatory bowel disease might share a similar pathogenesis. ${ }^{8}$ Therefore, ankylosing spondylitis and inflammatory bowel disease might develop in the same patient, but both conditions do not have a causal relationship, which is partially confirmed by our present study. Physicians who participate in care of patients with ankylosing spondylitis should take into consideration the possibility of inflammatory bowel disease, and vice versa.

\section{Shih-Wei Lai $\odot,^{1,2}$ Yu-Hung Kuo, ${ }^{3}$ Kuan-Fu Liao ${ }^{4,5}$}

${ }^{1}$ College of Medicine, China Medical University, Taichung, Taiwan

${ }^{2}$ Department of Family Medicine, China Medical University Hospital, Taichung, Taiwan
${ }^{3}$ Department of Research, Taichung Tzu Chi Hospital, Taichung, Taiwan

${ }^{4}$ College of Medicine, Tzu Chi University, Hualien, Taiwan

${ }^{5}$ Division of Hepatogastroenterology, Department of Internal Medicine, Taichung Tzu Chi Hospital, Taichung, Taiwan

Correspondence to Dr Kuan-Fu Liao; kuanfuliaog@gmail.com

Handling editor Josef S Smolen

Contributors S-WL contributed to the conception of the article, initiated the draft of the article, and has approved the final draft submitted. Y-HK and K-FL conducted data analysis.

Funding The authors have not declared a specific grant for this research from any funding agency in the public, commercial or not-for-profit sectors.

Competing interests None declared.

Patient consent for publication Not required.

Provenance and peer review Not commissioned; internally peer reviewed.

(c) Author(s) (or their employer(s)) 2021. No commercial re-use. See rights and permissions. Published by BMJ.

\section{Check for updates}

To cite Lai S-W, Kuo Y-H, Liao K-F. Ann Rheum Dis 2021;80:e144.

Received 24 September 2019

Accepted 26 September 2019

Published Online First 14 October 2019

Ann Rheum Dis 2021;80:e144. doi:10.1136/annrheumdis-2019-216362

\section{ORCID iD}

Shih-Wei Lai http://orcid.org/0000-0002-7420-1572

\section{REFERENCES}

1 Sun L-M, Muo C-H, Liang J-A, et al. Increased risk of cancer for patients with ankylosing spondylitis: a nationwide population-based retrospective cohort study. Scand J Rheumatol 2014;43:301-6.

2 Lai S-W, Lin C-L. Association between ankylosing spondylitis and chronic obstructive pulmonary disease in Taiwan. Eur J Intern Med 2018;57:e28-9.

3 Schreiber S, Colombel J-F, Feagan BG, et al. Incidence rates of inflammatory bowel disease in patients with psoriasis, psoriatic arthritis and ankylosing spondylitis treated with secukinumab: a retrospective analysis of pooled data from 21 clinical trials. Ann Rheum Dis 2019;78:473-9.

4 Ministry of Health and Welfare Taiwan. 2018 Taiwan health and welfare report[cited on September 1, 2019, English version]. Available: http://www.mohw.gov.tw

5 Palm 0, Moum B, Ongre A, et al. Prevalence of ankylosing spondylitis and other spondyloarthropathies among patients with inflammatory bowel disease: a population study (the IBSEN study). J Rheumatol 2002;29:511-5.

6 Ossum AM, Palm Øyvind, Lunder AK, et al. Ankylosing spondylitis and axial spondyloarthritis in patients with long-term inflammatory bowel disease: results from 20 years of follow-up in the IBSEN study. J Crohns Colitis 2018;12:96-104.

7 Fragoulis GE, Liava C, Daoussis D, et al. Inflammatory bowel diseases and spondyloarthropathies: from pathogenesis to treatment. World I Gastroenterol 2019;25:2162-76.

8 Bae JM, Choo JY, Kim K-J, et al. Association of inflammatory bowel disease with ankylosing spondylitis and rheumatoid arthritis: a nationwide population-based study. Mod Rheumatol 2017:27:435-40.

Table 1 Incidence of inflammatory bowel disease between ankylosing spondylitis group and non-ankylosing spondylitis group

\begin{tabular}{|c|c|c|c|c|c|c|c|c|c|c|}
\hline \multirow[b]{2}{*}{ Variable } & \multicolumn{4}{|c|}{ Ankylosing spondylitis } & \multicolumn{4}{|c|}{ Non-ankylosing spondylitis } & \multirow[b]{2}{*}{ Incidence rate ratio $(95 \% \mathrm{Cl})^{*}$} & \multirow[b]{2}{*}{$P$ value } \\
\hline & $\mathrm{N}$ & Event & Person- years & Incidence & $\mathrm{N}$ & Event & Person- years & Incidence & & \\
\hline All & 3003 & 18 & 12790 & 1.41 & 12012 & 166 & 92712 & 1.79 & 0.79 (0.48 to 1.28$)$ & 0.332 \\
\hline \multicolumn{11}{|l|}{ Sex } \\
\hline Male & 1767 & 10 & 7656 & 1.31 & 7068 & 101 & 54383 & 1.86 & $0.70(0.37$ to 1.35$)$ & 0.289 \\
\hline Female & 1236 & 8 & 5134 & 1.56 & 4944 & 65 & 38329 & 1.70 & 0.92 (0.44 to 1.91$)$ & 0.821 \\
\hline \multicolumn{11}{|c|}{ Age group (years) } \\
\hline $20-39$ & 1280 & 7 & 5607 & 1.25 & 5120 & 67 & 39390 & 1.70 & 0.73 (0.34 to 1.60$)$ & 0.436 \\
\hline $40-64$ & 1342 & 8 & 5579 & 1.43 & 5368 & 73 & 41488 & 1.76 & 0.81 (0.39 to 1.69$)$ & 0.583 \\
\hline $65-84$ & 381 & 3 & 1604 & 1.87 & 1524 & 26 & 11834 & 2.20 & 0.85 (0.26 to 2.81$)$ & 0.792 \\
\hline
\end{tabular}

Incidence: per 1000 person-years.

*Incidence rate ratio: ankylosing spondylitis vs non-ankylosing spondylitis (95\% CI). 